Editorial

\title{
Towards Sustainability: Photochemical and Electrochemical Processes Applied for Environmental Protection
}

\author{
Reyna Natividad $\left(\mathbb{D},{ }^{1}\right.$ Carlos Barrera-Díaz $\left(D,{ }^{1}\right.$ Carlos A. Martínez-Huitle $\mathbb{D},{ }^{2,3}$ \\ and Juan M. Rodríguez-Rodríguez $\mathbb{1}^{4}$ \\ ${ }^{1}$ Centro Conjunto de Investigación en Química Sustentable UAEM-UNAM, km 14.5 Carr. Toluca-Atlacomulco, Universidad \\ Autónoma del Estado de México, Toluca, MEX 50200, Mexico \\ ${ }^{2}$ Universidade Federal do Rio Grande do Norte, Campus Universitário s/n, Lagoa Nova, 59078-970 Natal, Brazil \\ ${ }^{3}$ Unesp, National Institute for Alternative Technologies of Detection, Toxicological Evaluation and Removal of Micropollutants and \\ Radioactives (INCT-DATREM), Institute of Chemistry, P.O. Box 355, 14800-900 Araraquara, SP, Brazil \\ ${ }^{4}$ Universidad Nacional de Ingeniería, Av. Tupac Amaru 210, Lima, Peru
}

Correspondence should be addressed to Reyna Natividad; reynanr@gmail.com, Carlos Barrera-Díaz; cebarrerad@uaemex.mx, Carlos A. Martínez-Huitle; mhuitle@hotmail.com, and Juan M. Rodríguez-Rodríguez; jrodriguez@uni.edu.pe

Received 13 May 2018; Accepted 13 May 2018; Published 23 September 2018

Copyright (C) 2018 Reyna Natividad et al. This is an open access article distributed under the Creative Commons Attribution License, which permits unrestricted use, distribution, and reproduction in any medium, provided the original work is properly cited.

In the last century, public policy around the globe was mainly focused on economic growth leaving out of this perspective, social concerns and the environment detriment that this merely economic approach was causing. It was until the last quarter of the 20th century that people started to be aware of the growing poverty and of the jeopardy of the planet as a result of human being activities. In consequence, the concept of sustainable development emerged in the United Nations as a call to all countries to integrate economic growth with social needs and environmental protection, in such a way that our activities as earth inhabitants stopped compromising the quality of life and needs satisfaction of future generations.

More recently, in 2016, effective 17 sustainable development goals established within the United Nations came officially. The embracement of these goals implies the design and execution of strategies that pursue poverty elimination by also addressing social needs and environmental protection. In this sense, the development of cleaner technologies and more effective sanitation systems is imperative and this has motivated the assessment of new technologies, many of them based on photochemical and electrochemical phenomena. Thus, this special issue aims to present original results regarding relevant aspects of such processes. For this purpose, ten manuscripts have been included.

Within the framework of photochemical processes, different issues were addressed ranging from novel photocatalysis approaches, photocatalyst synthesis improvements, emerging contaminant degradation, and photoreactor modeling and simulation.

Although $\mathrm{TiO}_{2}$ has been the preferred and therefore most assessed photocatalyst by the scientific community, the manuscripts included in this special issue show that there is still enough room for improvement taking as base such a material. Currently, one of the most important challenges regarding this material, that is, shifting its activation wavelength towards the visible region, is successfully addressed by synthesizing $\mathrm{Bi}$-modified $\mathrm{TiO}_{2}$ films where the bismuth titanates were found to be responsible of the improvement exhibited by photoactivity under simulated solar radiation.

By the first time, the synthesis and characterization of $\mathrm{SiO}_{2}$ monoliths coated with $\mathrm{TiO}_{2}$ was presented. This type of materials opens a window of photocatalytic process improvement not only from the point of view of photocatalysis but also from the corner of photoreactor design. Because of the exhibited characteristics, this type of material allows 
to conduct multiphase photoreactions in packed bed reactors under different flow regimes with the consequent effect on yield and selectivity. In this matter, the use of photocatalysis beyond organic compound removal has been also demonstrated but the oxidations were selectively conducted, achieving the selective production of formaldehyde from the photooxidation of methanol.

Regardless of the resulting material, it is observed that the sol-gel method remains as the preferred one for the photocatalyst synthesis and it can be also used as complimentary step of the hydrothermal method to obtain $1 \mathrm{D} \mathrm{TiO}_{2}$. It was shown that crystalline phase ratio, that is, anatase-rutile, not only dictates the well-known photoactivity of $\mathrm{TiO}_{2}$ to conduct oxidation reactions but also the resulting $1 \mathrm{D} \mathrm{TiO}_{2}$ shape (tubes or rods) and the bactericidal effect by using $1 \mathrm{D}$ photocatalyst. Interestingly, the effect of the morphology, tubes or rods, of the synthesized $1 \mathrm{D} \mathrm{TiO}_{2}$ is strongly correlated to the anatase-rutile ratio generated in the seeds by adjusting the $\mathrm{pH}$ and type of acid during the first step of the sol-gel method, hydrolysis.

An important issue within effluent sanitation is emerging contaminants. The challenge in this regard is not only their removal but also their detection. At this point, it is worth noticing that the adjective "emerging" does not mean that these compounds did not exist but that they were not actually detected by the available analytical techniques some decades ago. Thus, little or no attention was given to their detrimental effects on the environment. As fatal consequence, many compounds were not included in the current environmental legislations around the world so industries and many other service providers do not yet pay attention on their adequate disposal. Within this group of emerging contaminants, the widely used nonsteroidal anti-inflammatory drugs (NSAID) can be found. This is one of the topics that one of the included manuscripts focuses on. The results therein not only demonstrate that ketorolac (an NSAID) can be photochemically degraded but also, by analyzing a hospital effluent in a developing country and establishing a correlation with elsewhere published studies regarding toxicity, urge the update of environmental legislation in developing countries not only to regulate the pollutant discharge but also mainly to motivate the update of current treatment plants with the implementation of cutting-edge technologies, either photochemical or electrochemical. Interestingly enough, it also shows the feasibility of quantifying ketorolac by working out an adequate analytical method using standard techniques rather than sophisticated and expensive ones.

When dealing with chemical reactions activated by any source of energy, one should not forget the process core, the reactor. A nonadequate reactor design can lead to the subutilization of even the most efficient catalyst. An important tool on designing a reactor and elucidating the effect of reaction variables is modeling and simulation. This has been applied in one of the included manuscripts, not only to establish a relative simple mathematical model of an annular photoreactor but also to show the important variables whose effect should be observed at the time of assessing a photocatalyst. The established model managed to represent the radiant field within an annular photoreactor with high accuracy.
It also shows how the radiant field determines the permissible photocatalyst loading. Therefore, the presented results highlight the importance of optimizing both, radiant field and catalyst concentration, when assessing photoactivity or a photoprocess efficiency.

This special issue also deals with the assessment of electrochemical processes for environmental protection. In this context, the potential and importance of electrochemical processes are evidenced by the treatment of effluents of three different industries, paper, textile, and food. These works pursue the removal of organic compounds either by electrooxidation, electro-generated oxidant species, or by electrocoagulation. Within these works, a constant search for the improvement of existent electrochemical processes by applying innovative strategies such as coupling them with phytoremediation, for instance, can be appreciated. Although the latter did not lead to an improvement on chemical oxygen demand decrease, it was shown that it makes a significant difference on the total color and turbidity removal of a textile industry effluent. In another study, the efficiency of anodic oxidation conducted with boron diamond-doped electrodes was contrasted with electro-Fenton and the superiority of the former was established. Regarding the food industry effluent (chocolate manufacturing plant), the coupling of an electrocoagulation process with a filtration unit was concluded to be an alternative of pretreatment for such wastewater in order to significantly improve water quality.

For long time, both photochemical and electrochemical processes were highly criticized and their application was limited due to the required input of energy, to energize either an array of lamps or electrodes. It is undeniable that this aspect decreases, in many cases, the sustainability of a process. However, a twist of facts has been originated by the commercialization of solar photovoltaic modules. This topic is being addressed in one of the manuscripts by showing the feasibility of conducting an electrocoagulation process by using solar photovoltaic modules. Such research highlights the importance of correlating effluent residence time with current intensity and organic compound removal rate. As expected, current intensity was dependent on solar radiation and this fact motivates the further search of materials and devices capable of harvesting solar energy in a more efficient way than the existent ones. In this matter, a work that presents the effect of microcracks in silicon cells on the output power of the module is also included. Such work is a call to carefully look for microcracks in photovoltaic modules since they lead to current leakage.

Finally, it can be concluded that the recent results are sound and promising, even when important advances have been achieved by photochemical and electrochemical processes in the last decades; nevertheless, there are still challenges that deserve special attention in order to further strengthen one of the three pillars of sustainability and environmental protection.

\section{Acknowledgments}

We would like to express gratitude to all reviewers that, through their valuable comments, improved the overall 
quality of the manuscripts submitted to this special issue. We also acknowledge all authors for their contributions. Reyna Natividad and Carlos Barrera-Díaz are grateful to CONACYT (SNI and Project 168305), Mexico. Carlos A. Martínez-Huitle is grateful to National Council for Scientific and Technological Development (CNPq 465571/2014-0, 446846/2014-7, and 401519/2014-7) and FAPESP (2014/ 50945-4), Brazil. Juan M. Rodríguez-Rodríguez is grateful to MINEDU-CONCYTEC, Peru.

Reyna Natividad Carlos Barrera-Díaz Carlos A. Martínez-Huitle Juan M. Rodríguez-Rodríguez 

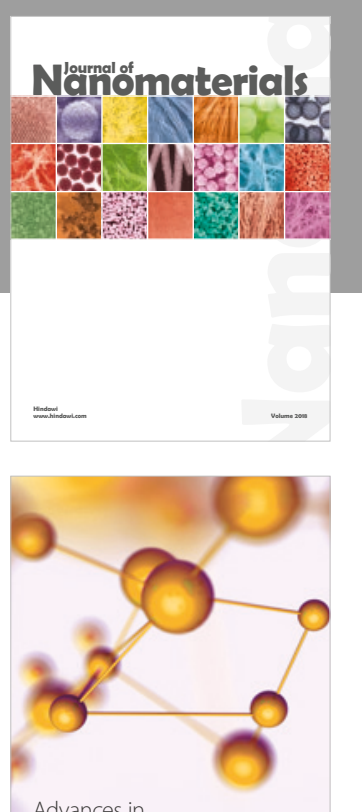

Physical Chemistry
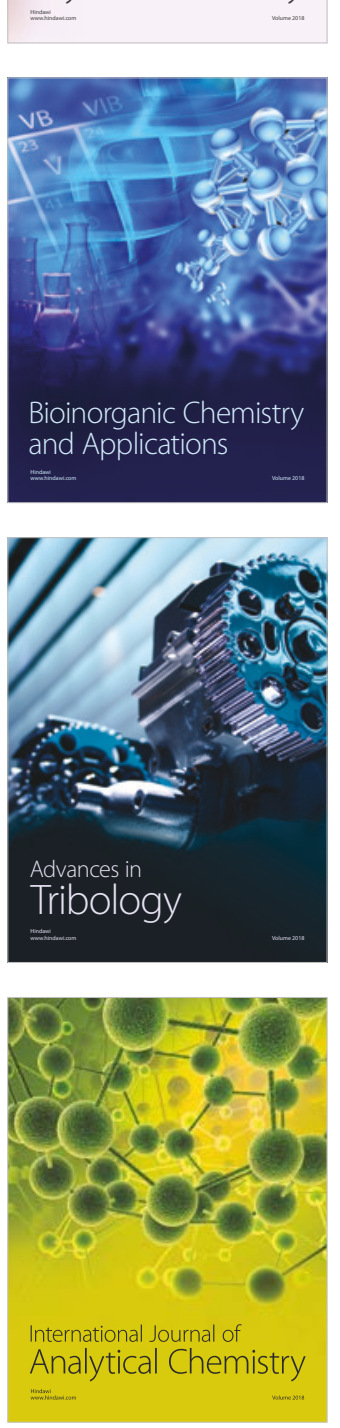

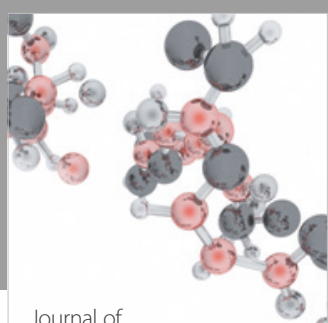

Analytical Methods

in Chemistry

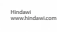

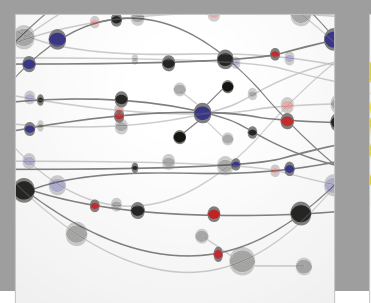

The Scientific World Journal

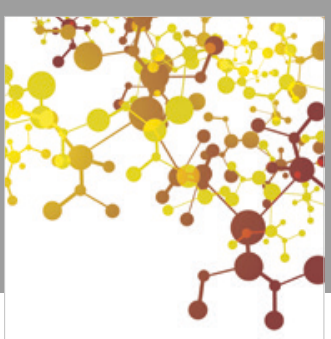

Journal of

Applied Chemistry
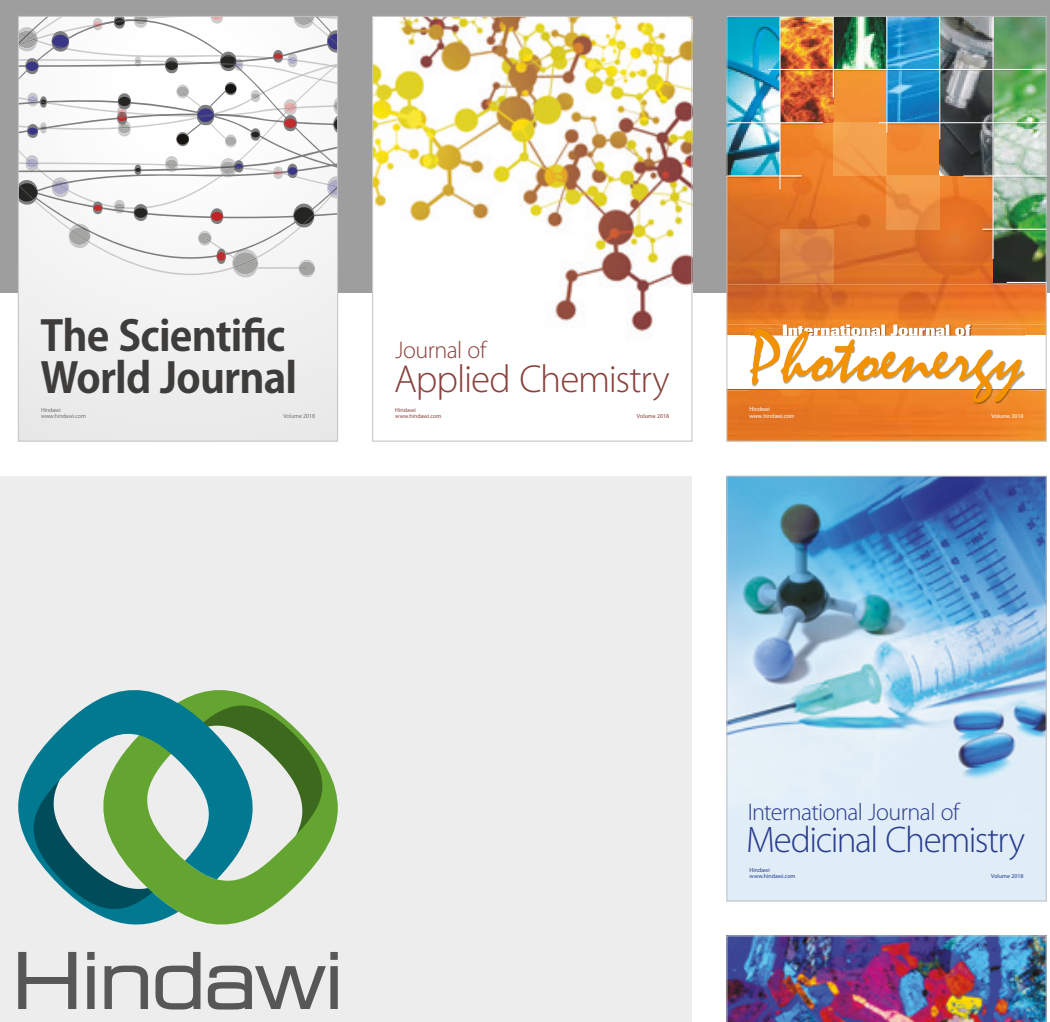

Submit your manuscripts at

www.hindawi.com
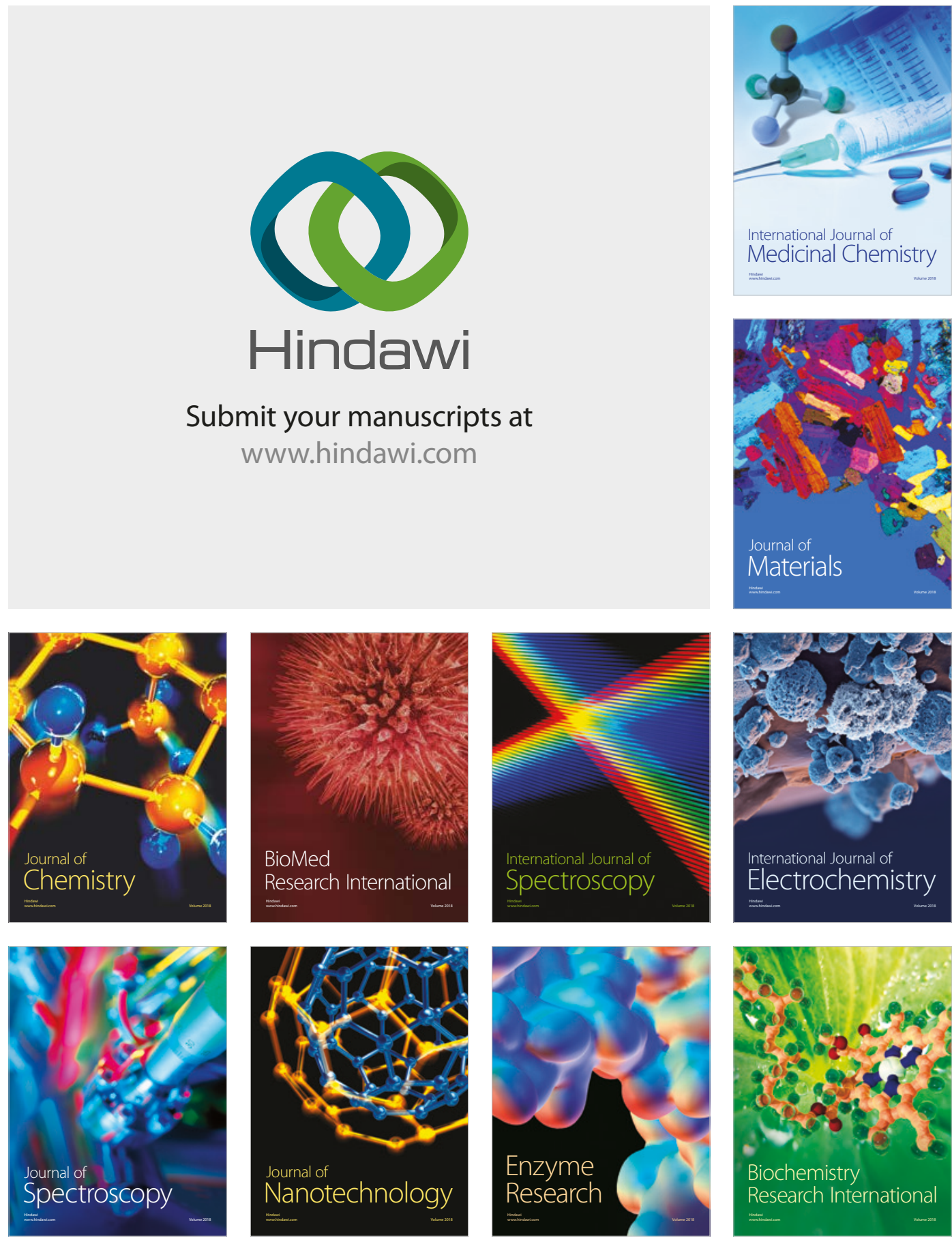
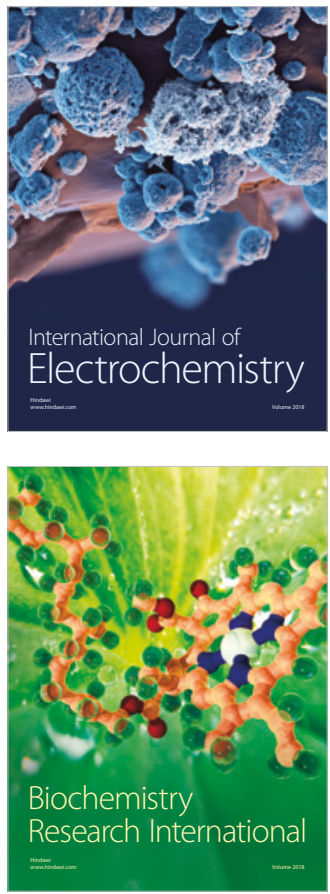